\title{
Recrystallization Characterizations of an Al-Zn-Mg-Cu-Zr Alloy during Multi-Pass Hot Rolling Simulation
}

\author{
Yan Liangming ${ }^{1}, \quad$ Shen $\mathrm{Jian}^{2}, \quad$ An $\mathrm{Di}^{1}, \quad$ Du Zhaoxin ${ }^{1}, \quad$ Zhang Jianbo ${ }^{3}$ \\ ${ }^{1}$ Inner Mongolia University of Technology, Huhhot 010051, China; ${ }^{2}$ General Research Institute for Non-ferrous, Beijing 100088, China; \\ ${ }^{3}$ Institute of Engineering \& Research, JiangXi University of Science and Technology, Ganzhou 341000, China
}

\begin{abstract}
This paper investigated the characterizations, using electron back-scattered diffraction (EBSD) and transmission electron microscope (TEM), of an $\mathrm{Al}-\mathrm{Zn}-\mathrm{Mg}-\mathrm{Cu}-\mathrm{Zr}$ alloy during multi-pass plain strain compression (PSC) performed to simulate the hot rolling system on Gleeble-1500D thermo-mechanical simulator. The results show that with increasing of the deformation, there are mainly two dynamic recrystallization mechanisms responsible for the development of new grain, including continuous dynamic recrystallization (CDRX) and geometry dynamic recrystallization (GDRX). The former is related to original grain boundaries bulging and sub-grain coalescence. The latter can be associated with serious deformation inhomogeneity. Besides, static recrystallization (SRX) happens during inter-pass time. The particles with a size of more than $1 \mu \mathrm{m}$ also result in the recrystallization.
\end{abstract}

Key words: $\mathrm{Al}-\mathrm{Zn}-\mathrm{Mg}-\mathrm{Cu}-\mathrm{Zr}$ alloy (AA7055); plain strain compression (PSC); geometry dynamic recrystallization; the second phase

$\mathrm{Al}-\mathrm{Zn}-\mathrm{Mg}-\mathrm{Cu}$ series alloys are extensively used in aeronautical and automotive industry due to their low densities and good mechanical properties ${ }^{[1,2]}$. One limitation of their uses is the low resistance to structural corrosion ${ }^{[2,3]}$. In order to make a compromise between mechanical strength and corrosion resistance, various heat treatment processes have been proposed to change the geometrical characteristic of precipitates $^{[1,3]}$. Besides, recrystallization fraction can also influence corrosion resistance ${ }^{[2,4]}$. It is generally accepted that the solution treatment is the main method to control recrystallization fraction for $7 \mathrm{xxx}$ series alloy plate when deformation is constant ${ }^{[2,5]}$. However, several studies introduced that thermomechanical processing could notably influence the recrystallization fraction in $\mathrm{Al}-\mathrm{Zn}-\mathrm{Mg}-\mathrm{Cu}$ alloy ${ }^{[4,6]}$. Thus, an understanding of recrystallization characterizations in Al-Zn$\mathrm{Mg}-\mathrm{Cu}-\mathrm{Zr}$ alloy (AA7055) during multi-pass rolling is of significance to control the recrystallization grain fraction in final production.

Dynamic recrystallization (DRX) has already been characterized a lot, and the mechanism has been well studied and understood. Three types of dynamic recrystallization are likely to occur: (i) discontinuous dynamic recrystallization (DDRX), i.e. the classical recrystallization, which operates by nucleation and grain growth; (ii) continuous dynamic recrystallization (CDRX), which involves the transformation of low angle boundaries into high angle boundaries; and (iii) geometric dynamic recrystallization (GDRX), generated by the fragmentation of the initial grains ${ }^{[7]}$.

Present works ${ }^{[8,9]}$ have shown the dynamic recrystallization (DRX) occurs in $\mathrm{Al}-\mathrm{Zn}-\mathrm{Mg}-\mathrm{Cu}$ series alloy in single-pass compression at elevated temperature. However, it generally needs several passes rolling to get qualified aluminium alloy plates. Due to high strain energy after rolling at elevated temperature, various metallurgical phenomenon may take place during interval between passes, such as static recovery (SRV), static recrystallization (SRX) and metadynamic recrystallization $(\mathrm{MDRX})^{[7,10]}$. Nevertheless, to date there were not detailed reports of recrystallization characterizations of $\mathrm{Al}-\mathrm{Zn}-\mathrm{Mg}-\mathrm{Cu}-\mathrm{Zr}$ alloy (AA7055) in multi-pass rolling.

In this study, researchers aim at providing detailed

Received date: November 25, 2016

Foundation item: National Natural Science Foundation of China (51461017); Natural Science Foundation of Inner Mongolia (2011bs0802)

Corresponding author: Yan Liangming, Ph. D., Associate Professor, School of Material Science and Engineering, Inner Mongolia University of Technology, Hohhot 010051, P. R. China, E-mail: yanliangming@126.com 
assessment of recrystallization characterizations of $\mathrm{Al}-\mathrm{Zn}-\mathrm{Mg}-$ $\mathrm{Cu}-\mathrm{Zr}$ (AA7055) alloy in multi-pass hot rolling simulation.

\section{Experiment}

The chemical composition of $\mathrm{Al}-\mathrm{Zn}-\mathrm{Mg}-\mathrm{Cu}-\mathrm{Zr}$ aluminium alloy contains by mass fraction (wt\%), approximately: aluminum-7.87 zinc-2.16 magnesium-2.05 copper-0.12 zirconium. The homogenized ingot was machined to dimensions of $10 \mathrm{~mm} \times 20 \mathrm{~mm} \times 15 \mathrm{~mm}$. According to the industrial rolling process of $\mathrm{Al}-\mathrm{Zn}-\mathrm{Mg}-\mathrm{Cu}$ serials aluminum alloys, multi-pass PSC was performed by Gleeble-1500D thermos-mechanical simulator. The PSC process included 18 passes and total strain of 1.61. Graphite pieces were used as lubricant to reduce friction between anvils and specimen during hot compression. The samples undergoing different reductions were quenched in water to keep the microstructure. Microstructures of longitudinal section of the compressed specimens were observed by transmission electron microscope (TEM) and electron back-scattering diffraction (EBSD). The discs were ground to a thickness of about $50 \mu \mathrm{m}$, and then were subjected to twin-jet electropolishing. TEM observation was made on a JEM-2000FX transmission electron microscope operated at $180 \mathrm{kV}$. Orientation data of EBSD maps were obtained using an HKL Technology Channel5 EBSD system interfaced to a Shimadzu SSX-550 SEM. A step size of $0.7 \mu \mathrm{m}$ was used. In images of reconstructed grain boundaries, coarse black line: $\geq 15^{\circ}$, fine black line: $10^{\circ} \sim 15^{\circ}$, blue line: $8^{\circ} \sim 10^{\circ}$, pink line: $5^{\circ} \sim 8^{\circ}$, red line: $3^{\circ} \sim 5^{\circ}$

\section{Results and Discussion}

\subsection{Multi-pass compression of flow stress curve}

Parts of samples compressed with different passes are shown in Fig.1. From sample morphology, there is notable spread along the longitudinal direction of the punch, so it is necessary to modify the true stress-strain curve from the Gleeble-1500D thermos-mechanical simulator. The modified true stress-true strain curve is presented in Fig.2. The flow stress increases with strain and rapidly reaches peak value in each compression. The peak stresses during multi-pass compression are affected by the parameter of Zener-Hollomon $(Z)$, which is defined as:

$$
Z=\dot{\varepsilon} \exp \left(\frac{Q}{R T}\right)
$$

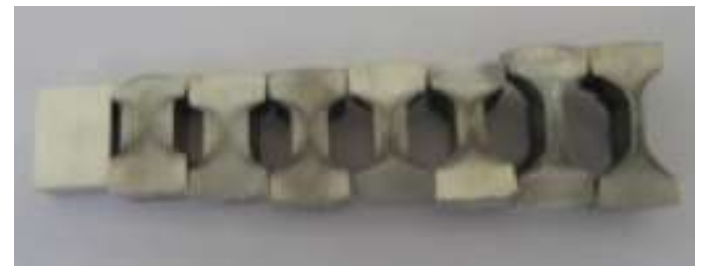

Fig.1 Morphology of samples compressed by multi-pass with different strains: $0.111,0.376,0.543,0.744,0.860,0.994$ and 1.61 where $R$ is gas constant, $T$ is thermodynamic temperature, $Q$ is deformation activation energy, $\dot{\varepsilon}$ is strain rate. According to the theory in Ref. [11], the peak stress should increase when $Z$ rises. However, in the true stress-true strain curve, parts of peak stresses are approximately equal. The softening processes of recovery and recrystallization during deformation and interval time account for phenomena above.

\subsection{Microstructure characteristics}

Fig. 3 shows the typical EBSD image of the microstructure of the sample compressed by 13 passes and then water-quenched, which corresponds to a total strain of 0.74 . Micrograph in Fig.3a is the typically deformed microstructure. Some un-recrystallized and hence work-hardened, coarse grains are highly elongated crosswise to the compression axis. The new fine grains develop at original grain boundaries and triple junction and the fraction of the new grains amounts to $\sim 3 \%$ (in Fig. 3b); their average size is $\sim 3 \mu \mathrm{m}$.

There are a great many sub-grain boundaries with misorientation less than $8^{\circ}$ and bulging original boundaries (Fig.3b). Sub-boundaries with medium- to high-angle misorientation can effectively separate the bulges from parent grains $^{[12]}$. The development of strain-induced grain boundaries is caused by the local build-up of strain gradients in the vicinities of initial grain boundaries. The misorientations in grain interiors which are located far from grain boundary are less than $5^{\circ}$, while misorientations above $8^{\circ}$ are close to the initial boundary (Fig.3b). The bulge that leads to the formation of the recrystallization nucleus is enclosed by high angle boundaries (HABs). Therefore, initial boundaries and their junctions are preferable sites for DRX nucleation during hot working $^{[9,12,13]}$.

Fig. $3 \mathrm{c}$ presents the accumulative misorientation along line A in Fig.3a, from the grain interior to the initial boundary. With the decrease of the distance reaching initial boundary, the accumulative misorientation increases. This proves that sub-grain rotates, which results in the sub-grain misorientation changing ${ }^{[14]}$. The green dots in Fig.3a are the second phase and the green dot in the position $\mathrm{B}$ lies in grain interior. The line misorientation along the line in the position $\mathrm{B}$ in Fig.3a is shown in Fig.3d. It is noted that there are high-angle boundaries

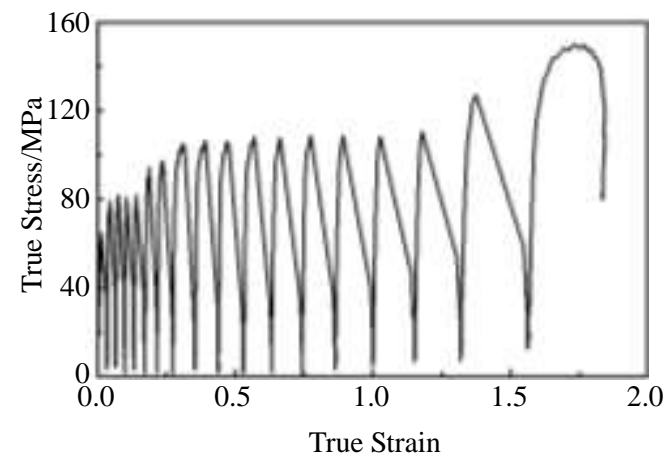

Fig.2 Flow stress-true strain curve for multi-pass compression 


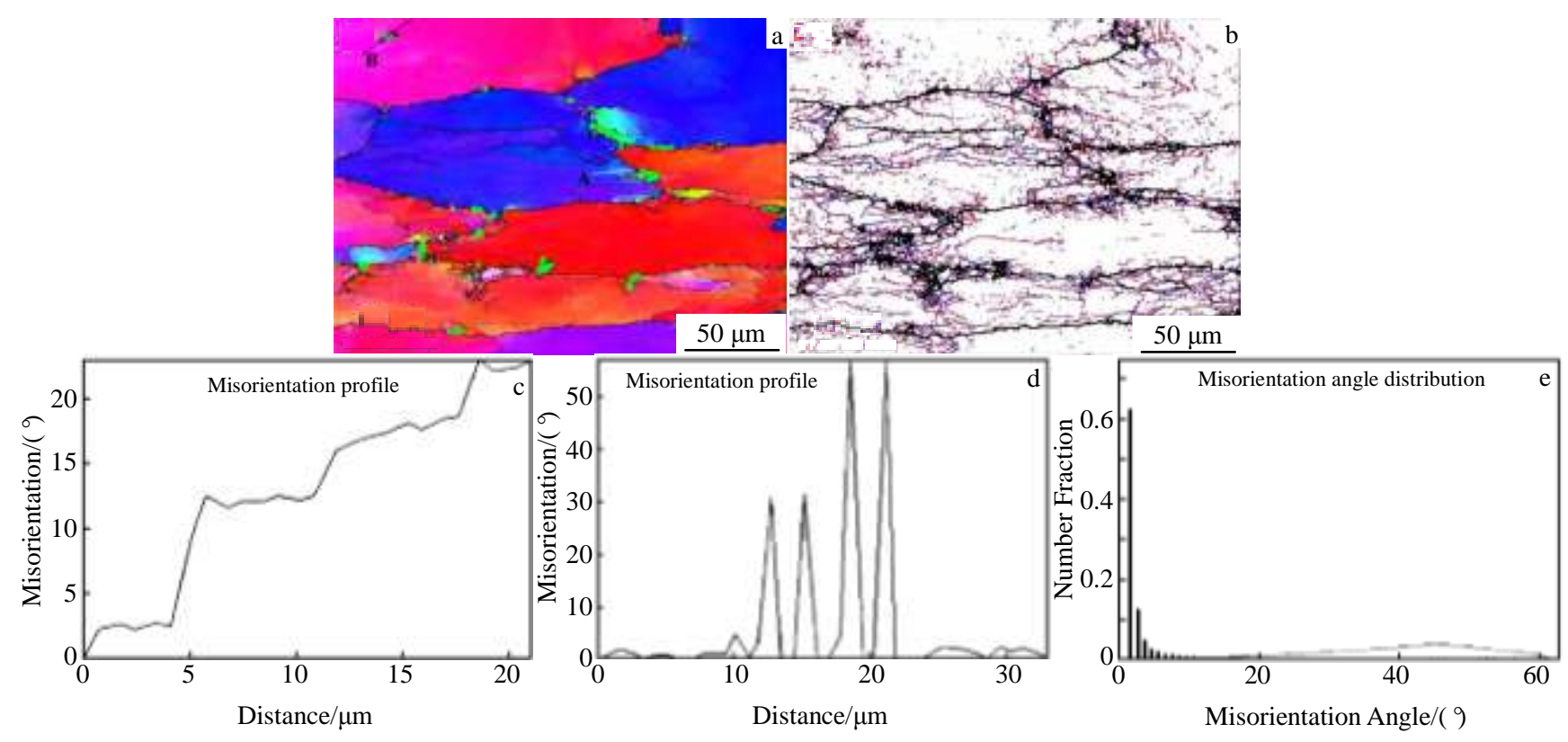

Fig.3 EBSD images of the sample compressed by 13 passes $(\varepsilon=0.74)$ and water-quenching: (a) orientation imaging microscope, (b) map of reconstructed grain boundaries, (c) cumulative misorientation along line A in Fig.3a, (d) line misorientation along line B in Fig.3a, and (e) misorientation angular distributions

of more than $15^{\circ}$, which confirms that recrystallization occurs. The second phase in grain interior can promote recrystallization nucleation. Fig.3e is the statistical result of misorientation angle distribution. The fraction of the high-angle boundaries is less than 5\%. Fig.4 shows sub-structure in the sample. There are fine sub-grains with around $2 \mu \mathrm{m}$ in size and amount of dislocations, especially near sub-grain boundaries. Fine second-phase particles appear at sub-grain boundary and dislocation.

The typical microstructures of sample compressed by 13 passes, held for $180 \mathrm{~s}$ and then water-quenched are shown in Fig.5. Micrograph of it is still the typically deformed microstructure. The new grains directed by arrow take place along the original grain boundaries (in Fig.5a), which are so-called necklace microstructure ${ }^{[7]}$. The fraction of the new recrystallization grains amounts to $\sim 5 \%$ (in Fig. 5 b); their average size is $\sim 5 \mu \mathrm{m}$.

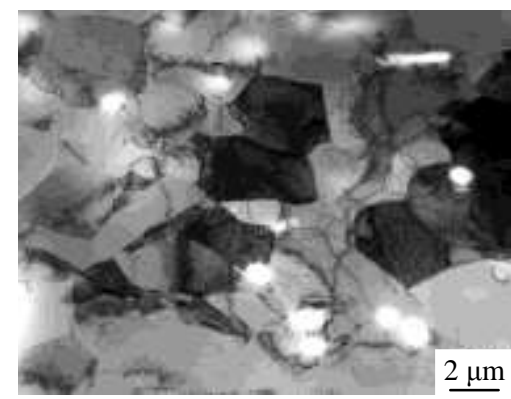

Fig.4 TEM image of substructure in the sample compressed by 13 passes $(\varepsilon=0.74)$ and water-quenched
Comparing Fig.3e with Fig.5c, the high-angle misorientation fraction notably increases. From Fig.6, it can be known that the sub-grain boundary directed by arrow is moving to the sub-grain with high density dislocation. Microstructure in Fig. 6 is of bigger sub-grain size and lower dislocations density than it is in Fig.4. These phenomena confirm that static recrystallization (SRX) can happen in interval between passes.

Fig.7 presents EBSD micrograph obtained from the sample with a total strain of 1.61 (compressed by 18 passes). Great many of recrystallization grains develop at original boundaries (in Fig.7a). Besides, a lot of new grains form in the region with a great many second-phase particles. The sub-grain sizes range from 1 to $3 \mu \mathrm{m}$ in Fig.8a and the small second phases pin the dislocation and low-angle boundaries in Fig.8b. Fig.7c shows the line misorientation along line A (in Fig.7b) according with the compression direction. Grain heights are significantly different along the compression direction, as confirm uneven deformation occurs during compression. The minimum height of the deformed grain is around $5 \mu \mathrm{m}$ and there have one or two low-angle boundaries between two high-angle boundaries.

\subsection{Recrystallization mechanism}

The present results reveal that different recrystallization mechanisms are responsible for the new grain development under various deformation conditions. The initiation of DRX in $\mathrm{Al}-\mathrm{Zn}-\mathrm{Mg}-\mathrm{Cu}-\mathrm{Zr}$ alloy (AA7055) is characterized by serrated grain boundaries, as shown in Fig.3a, which is closely related to the strain-induced grain boundary migration. This kind of grain boundary morphology implies that the recry- 

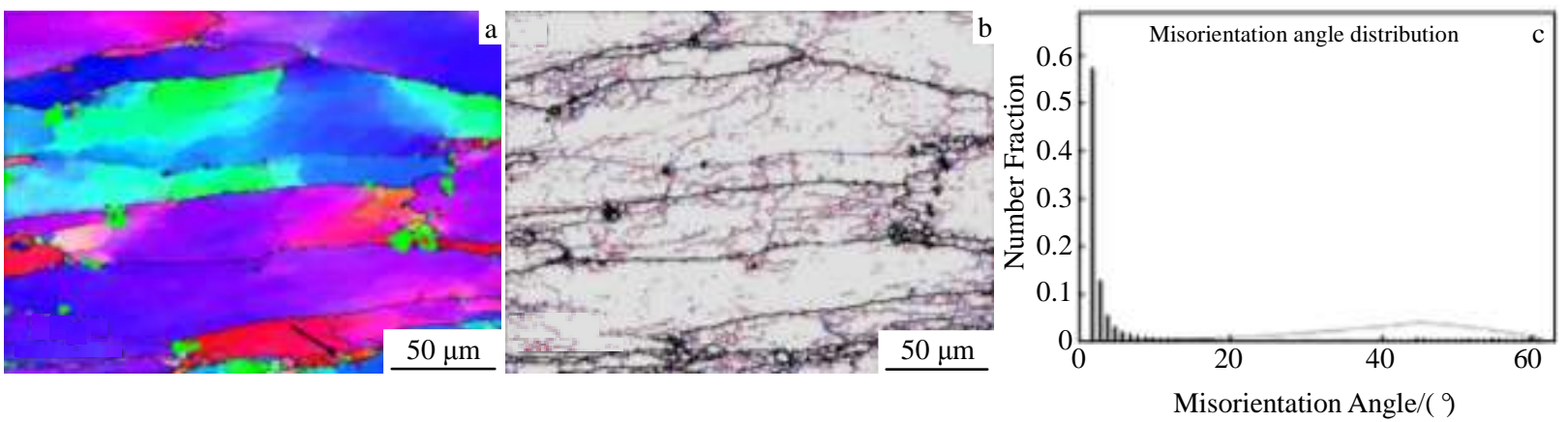

Fig.5 EBSD image of the sample compressed by 13 passes, held temperature for $180 \mathrm{~s}$ and then quenched by water: (a) orientation imaging microscope, (b) map of reconstructed grain boundaries, and (c) misorientation angular distributions

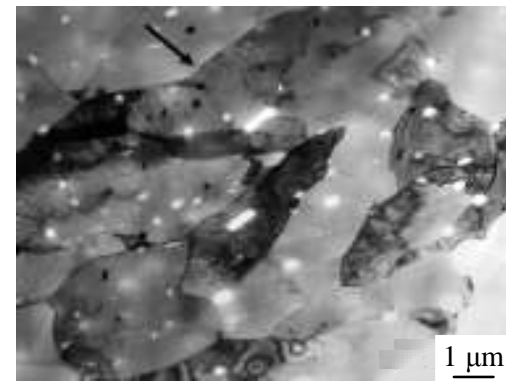

Fig.6 TEM image of substructure in the sample compressed by 13 passes $(\varepsilon=0.74)$, held temperature for $180 \mathrm{~s}$ and then quenched by water

stallization mechanism belongs to the continuous dynamic recrystallization $(\mathrm{CDRX})^{[15]}$. The cumulative misorientations (Fig.3c) along the line A (Fig.3a) shows the large orientation gradients which develop at the boundaries, particularly within the serration. The sub-grain rotation owing to grain boundary shearing would result in the evolution of local orientation and strain gradients, contributing to the nucleation of DRX grains. It can be concluded from above results that the DRX nucleation of AA7055 aluminium alloy may be operated by bulging of the original grain boundaries, assisted by sub-grain rotation.

Uneven deformation occurs in AA7055 aluminium alloy during hot compression (in Fig.7). Along the compression direction (in Fig.7b), the maximum grain height is approximate up to $50 \mu \mathrm{m}$; nevertheless, the height in grain with severe deformation is about $5 \mu \mathrm{m}$ that is almost double of the sub-gain size (in Fig.8a). Fine new grains are generated through the fragmentation of the initial grains compressed severely. According to the relevant description ${ }^{[16]}$, the recrystallization has a characteristic of the geometric dynamic recrystallization (GDRX). Mcqueen ${ }^{[17]}$ firstly proposed GDRX and believe that when the pure aluminium was compressed, the original boundaries became flat-shaped and serrated. When the size of the compressed grains was approximately double to the sub-grain size, part of original grain boundaries are contacted and broken, and finally fine new grains formed. GDRX occurs in the alloy which has undergone severe deformation, especially uneven deformation ${ }^{[16]}$. Deformation temperature, strain rate, strain and initial microstructure have main effect on uneven deformation which leads to microstructure uniformity ${ }^{[18,10]}$, so the uneven deformation should be avoided.

New recrystallization grain is not only attributed to DRX, but also it results from SRX. Dynamic recrystallization just partly takes place during deformation at high temperature, and thus the sample has a lot of crystal defects such as sub-grain boundaries, dislocation and vacancy. Those defects are unstable and become the driving force of SRV, MDRX and
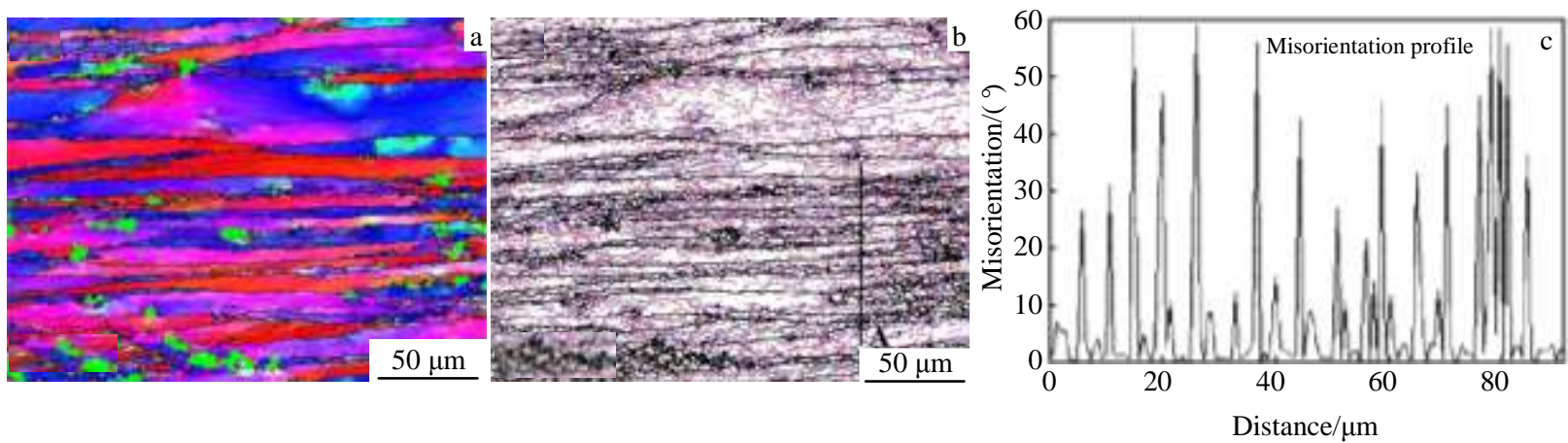

Fig.7 EBSD images of the sample compressed by 18 passes ( $\varepsilon=1.61$ ): (a) orientation imaging microscope, (b) map of reconstructed grain boundaries, and (c) line misorientation along line A in Fig.7b 


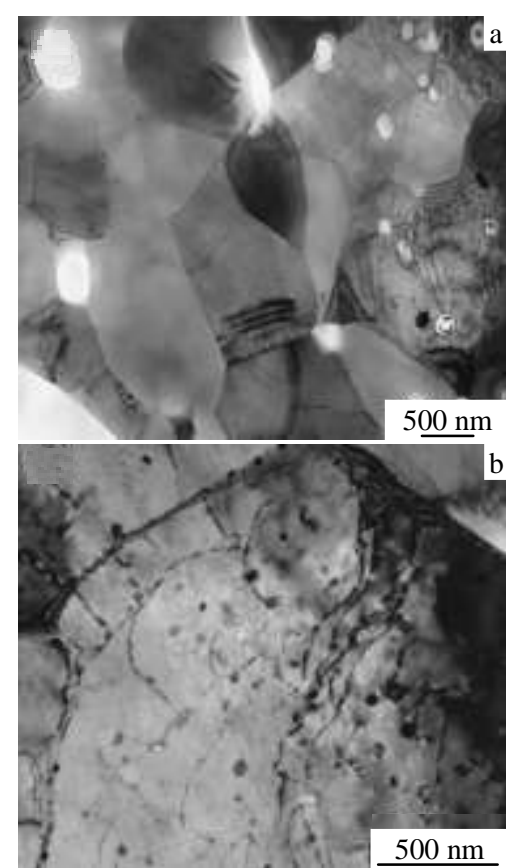

Fig.8 TEM images of substructure in the sample compressed 18 passes ( $\varepsilon=1.61$ ): (a) sub-grain and (b) the second phases

SRX. The growth of some new dynamically recrystallized grains is not sufficient enough in the compressed sample in Fig.3. Consequently, SRX and MDRX may take place during inter-pass time. High dislocation density shown in Fig.4 provided driving force for the grain boundaries and sub-grain boundaries to migrate. The growing sub-grains may continue to grow up by sub-grain rotation and coalescence due to energy gradient. Therefore, the size of the recrystallized grains after compression and holding for some time shown in Fig.5b are bigger than that of dynamically recrystallized ones shown in Fig.3b, and the fraction of high angle grain boundaries increases, as shown in Fig.3e and Fig.5c. So the recrystallization grain size and fraction can be controlled through regulating the interval time between passes. It is important to control the microstructure and properties of the hot-rolling products.

\subsection{Effect of the second phase on recrystallization}

The alloy element in pure aluminium can efficiently decrease stack fault energy. For example, $0.36 \% \mathrm{Mg}$ can cause the stack fault energy of the pure aluminium to decrease from 200 to 50 $\mathrm{J} / \mathrm{m}^{2}{ }^{[19]}$. Excessive alloy element in the alloy results in the particles formation and they are helpful to control microstructure. For example, coarse particles may be used to promote recrystallization through particle stimulated nucleation of recrystallization (PSN). Many wrought alloys also make use of fine particles for the purpose of grain structure control. For example, in wrought aluminium alloys, the elements for precipitate are added in commercial alloy. Precipitates can prevent recrystallization or grain growth during in the thermosmechanical process via the Smith-Zener pinning effect ${ }^{[20]}$.
The as-homogenized Al-Zn-Mg-Cu-Zr alloy has a great many second phases with different sizes, including $S$ $\left(\mathrm{CuMgAl}_{2}\right), \mathrm{T}(\mathrm{AlZnMgCu}), \mathrm{AlMnFeSi}, \eta\left(\mathrm{MgZn}_{2}\right)$, and $\theta$ $\left(\mathrm{Al}_{2} \mathrm{Cu}\right)^{[21,22]}$. These second-phase particles (green points) with a size of more than $1 \mu \mathrm{m}$ can be observed in Fig.3a, Fig.5a and Fig.7a. It is well known that hard micron-scale, the second-phase particle can increase the rate of dislocation generation and develop deformation zones in the matrix and large local misorientation gradients ${ }^{[23]}$. New high angle boundaries can form within such deformation zone with relatively low strains. Thus a lot of recrystallization grains form surrounding the particles. However, the particles with a size range of $20 \sim 100 \mathrm{~nm}$, such $\mathrm{Al}_{3} \mathrm{Zr}$ forming during homogenization heat-treatment, $\eta^{\prime}$ or/and $\eta$ phase precipitating during deformation, disperse on the dislocation and sub-grain boundaries in Fig.5, Fig.6 and Fig.8 which pin dislocations and sub-grain boundaries and hinder the sub-grain to grow up and recrystallization.

\section{Conclusions}

Multi-pass plain strain compression (PSC) test was carried out to simulate the industrial rolling process of Al-Zn-Mg$\mathrm{Cu}-\mathrm{Zr}$ alloy (AA7055). Continuous DRX can be found in the sample at true strain of 0.74 and the main nucleation mechanisms of CDRX are sub-grain coalescence and sub-grain growth. When true strain reaches 1.61, geometric dynamic recrystallization may be another mechanism for the formation of new grains. SRX takes place during the inter-pass time. PSN is also one of the main nucleation mechanisms.

\section{References}

1 Rometsch P, Zhang Y, Knight S. Transactions of Nonferrous Metals Society of China[J], 2014, 24(7): 2003

2 Bobby K M, Raja V S. Engineering Fracture Mechanics[J], 2010, 77: 249

3 Knight S P, Birbilis N, Muddle B C et al. Corrosion Science [J], 2010, 52: 4073

4 Deng L Y, Zhang Y Y, Wan L et al. Materials Science \& Engineering $A[\mathrm{~J}], 2012,554: 33$

5 Chen S Y, Chen K H, Dong P X et al. Journal of Alloys and Compounds[J], 2013, 581: 705

6 Yan L M, Shen J, Li Z B et al. Transactions of Nonferrous Metals Society of China[J], 2013, 23(3): 625

7 Humphreys F J, Hatherly M. Re-crystallization and Related Annealing Phenomena[M]. Oxford: Pergamon Press, 2004: 427

8 Lin Y C, Li L T, Xia Y C et al. Journal of Alloys and Compounds[J], 2013, 550: 438

9 Zhang H, Jin N P, Chen J H. Transactions of Nonferrous Metals Society of China[J], 2011, 21(3): 437

10 Dehghan-Manshadi A, Barnett M R, Hodgson P D et al. Metallurgical and Materials Transactions A[J], 2008, 39(6): 1371

11 Kocks U F, Mecking H. Progress in Materials Science[J], 2003, 
48(2): 171

12 Dudova N, Belyakov A, Sakai T et al. Acta Materialia[J], 2010, 58: 3624

13 Yan L M ,Shen J, Li J P et al. Materials Science Forum[J], 2010, 650: 295

14 Huang Y, Humphreys F J. Acta Materialia[J], 1997, 45(11): 4491

15 Drury M D, Humphreys F J. Acta Metallurgica[J], 1986, 34: 2259

16 Zhang H, Zhong H P, Peng D S. Journal Central South University Technology[J], 1997, 30: 407 (in Chinese)

17 Humphreys F J, Hatherly M. Re-crystallization and Related Annealing Phenomena[M]. Oxford: Pergamon Press, 2004: 462
18 Mcqueen H J, Ryum C N. Journal of Metallurgy[J], 1985, 14: 183

19 Hu H E, Zhen L, Yang L. Materials Science \& Engineering A[J], 2008, 488: 64

20 Furu T. Acta Materialia[J], 1999, 47(5): 2377

21 Robson J D. Materials Science \& Engineering A[J], 2004, 382(2): 112

22 Mondal C, Mukhopadhyay A K, Raghu T et al. Materials Science \& Engineering A[J], 2007, 455(10): 673

23 Apps P J, Bowen J R, Prangnell P B. Acta Materialia[J], 2003, 51: 2811

\title{
多道次热轧模拟过程中 Al-Zn-Mg-Cu-Zr 合金的再结晶特征
}

\author{
间亮明 ${ }^{1}$, 沈 健 $^{2}$, 安 迪 $^{1}$, 杜赵新 ${ }^{1}$, 张建波 ${ }^{3}$ \\ (1. 内蒙古工业大学, 内蒙古 呼和浩特 010051) \\ (2. 北京有色金属研究总院，北京 100088)
}

(3. 江西理工大学 工程研究院, 江西 赣州 341000)

\begin{abstract}
摘 要: 采用 Gleeble-1500D 热模拟试验机根据设计的轧制工艺对 7055 合金进行多道次热压缩试验, 模拟其企业热轧过程, 采用电子背 散射衍射和透射电镜研究了再结晶特征。在不同变形条件下, 表现出不同的再结晶机制, 主要动态再结晶机制有连续动态再结晶和几何 动态再结晶。前者的形核机制主要为原始晶界弓出形核和亚晶合并形核; 后者归因于严重的不均匀变形。在道次间的间隙期间, 静态再 结晶发生。另外, 尺寸大于 $1 \mu \mathrm{m}$ 的第二相也促进再结晶。
\end{abstract}

关键词：Al-Zn-Mg-Cu-Zr 合金(AA7055)；平面应变压缩；几何动态再结晶；第二相

作者简介：间亮明, 男, 1979 年生, 博士, 副教授, 内蒙古工业大学材料科学与工程学院, 内蒙古 呼和浩特 010051 , E-mail: yanliangming@126.com 